\title{
Raising the Dead without a Red Sea-Dead Sea project? Hydro-economics and governance
}

\author{
D. E. Rosenberg \\ Department of Civil and Environmental Engineering and Utah Water Research Laboratory, \\ Utah State University, Logan, Utah, USA
}

Received: 30 November 2010 - Published in Hydrol. Earth Syst. Sci. Discuss.: 21 December 2010

Revised: 11 April 2011 - Accepted: 14 April 2011 - Published: 20 April 2011

\begin{abstract}
Seven decades of extractions have dramatically reduced Jordan River flows, lowered the Dead Sea level, opened sink holes, and caused other environmental problems. The fix Jordan, Israel, and the Palestinians propose would build an expensive multipurpose conveyance project from the Red Sea to the Dead Sea that would also generate hydropower and desalinate water. This paper compares the Red-Dead project to alternatives that may also raise the Dead Sea level. Hydro-economic model results for the Jordan-Israel-Palestinian inter-tied water systems show two restoration alternatives are more economically viable than the proposed Red-Dead project. Many decentralized new supply, wastewater reuse, conveyance, conservation, and leak reduction projects and programs in each country can together increase economic benefits and reliably deliver up to $900 \mathrm{MCM} \mathrm{yr}^{-1}$ to the Dead Sea. Similarly, a smaller Red-Dead project that only generates hydropower can deliver large flows to the Dead Sea when the sale price of generated electricity is sufficiently high. However, for all restoration options, net benefits fall and water scarcity rises as flows to the Dead Sea increase. This finding suggests (i) each country has no individual incentive to return water to the Dead Sea, and (ii) outside institutions that seek to raise the Dead must also offer countries direct incentives to deliver water to the Sea besides building the countries new infrastructure.
\end{abstract}

\section{Introduction}

The Jordan River basin states have long faced water scarcity with plans, proposed allocations, diversions, reservoirs, and treaties to address scarcity dating back a century and longer (Beaumont, 1997; Lowi, 1993; Wolf, 1995). As a result just 100 million cubic meters per year $\left(\mathrm{MCM} \mathrm{yr}^{-1}\right)$ of the $1000+\mathrm{MCM} \mathrm{yr}^{-1}$ that historically flowed in the lower Jordan River now reach the river's outlet at the Dead Sea (Beaumont, 1997; Raz, 2009; Yechieli et al., 1998). The Dead Sea level has fallen - 30 m since 1960 and $1.2 \mathrm{~m}$ in 2009 alone with declines causing land subsidence, sink holes, groundwater contamination, reduced mineral extraction and tourism, plus other problems (Asmar and Ergenzinger, 2002;Glausiusz, 2010; Lensky et al., 2005; Yechieli et al., 1998; Salameh and El-Naser, 2008).

In response, Jordan, Israel, and the Palestinians seek to build a $180 \mathrm{~km}$ conveyance project from the Red Sea at Aqaba north to the Dead Sea (Glausiusz, 2010; Hussein, 2007). This Red-Dead project would use a $400 \mathrm{~m}$ elevation drop to generate hydropower, desalinate some conveyed water, dump brine waste into the Dead Sea to restore the lake level, and pump desalinated water $1000 \mathrm{~m}$ up to major urban areas in Jordan and possibly Palestine and Israel.

Although estimates exist of Israeli, Jordanian, and Palestinian willingness-to-pay to restore the Dead Sea (Becker and Katz, 2009), system-wide benefits and impacts of the Red-Dead project and alternatives have not been quantified (Arbitbol, 2006). Further, the project requires at least \$US 5 billion in donor funds (Glausiusz, 2010; Hussein, 2007) and the World Bank is now assessing the project for environmental, social, and economic feasibility (2010). The Bank's assessment will focus on different Red-Dead project alignments (2010) rather than alternative infrastructure, operations, or governance to "raise the Dead" Sea level. Potential alternatives could include:

- each country cuts back water use by its agricultural users in the Jordan Valley,

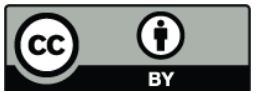

Correspondence to: D. E. Rosenberg

(david.rosenberg@usu.edu)

Published by Copernicus Publications on behalf of the European Geosciences Union. 
- release more freshwater from the Sea of Galilee (Lake Kinneret, Tiberias), dams on the Yarmouk, and other tributaries,

- release more freshwater from the Galilee and substitute foregone water with water desalinated on the Mediterranean seacoast, or

- build decentralized new water supply, wastewater treatment and reuse projects plus implement targeted water conservation and leak reduction programs to allow each country to forgo or substitute use of Jordan River water.

Here, I (i) identify hydrologic and economic impacts of the Red-Dead project and alternatives, (ii) quantify impacts among countries and as a function of the flow delivered to the Dead Sea, and (iii) suggest governance for viable approaches. To do this I extend the hydro-economic Water Allocation System (WAS) model for Israel, Palestine, and Jordan (Fisher et al., 2005; Rosenberg et al., 2008) to include and allow return flows from agriculture, brine waste from desalination, multiple water quality types to meet a minimum in-stream flow requirement, and fixed-increment infrastructure capacity expansions. These extensions represent important components of the flow balance for the Dead Sea, flow requirements to restore the Dead Sea level, and limits to build large infrastructure such as the Red-Dead project. They are needed to quantify impacts both of restoration alternatives and as a function of flow delivered to the Dead Sea. Sections 2 and 3 overview the hydro-economic modelling approach and describe model extensions. Subsequent sections present updated model data for the three countries, model results, and implications for governance. Section 7 concludes.

\section{Hydro-economic modelling approach}

Hydro-economic models have seen wide use by academics for over 4 decades (Howe and Linaweaver, 1967; Milliman, 1963; Harou et al., 2009) and are suited to assess local and regional water management activities because they can mathematically integrate into a single coherent framework the spatially distributed and disaggregated hydrologic, engineering, economic, environmental, operations, and policy aspects of complex water systems (Harou et al., 2009). Hydrologic water balance components such as river flows, evaporation, natural groundwater recharge and discharge, and return flows combine with relevant engineered diversions, reservoirs, pipelines, canals, well fields, desalination, wastewater treatment plants, and other components to form a node-link network. Costs are specified for flows along links or other water provision, treatment, and disposal activities at nodes. Economic demands such as urban, industrial, and agricultural uses are located at nodes and described by demand functions that express the value or benefits derived from the water volume delivered.
A central hydro-economic model concept is that water demands are not fixed delivery requirements but rather functions where volumes of water use at different times and places have varying total and marginal economic values (Harou et al., 2009). The model identifies water allocations to nodes and through links that maximize system-wide net benefits with net benefits quantified as the area between the demand and cost curves. Allocations are subject to physical, hydrologic, engineering, operational, and policy constraints and limits.

Models include environmental water uses - such as flow to the Dead Sea - in two ways. Where possible, models quantify environmental demand curves using revealed preference, travel cost, hedonic pricings, stated preference, or other econometric estimation methods (Young, 2005). Then, they locate demand curves at model nodes like other economic demands. This first approach is often only partial and controversial (Becker and Katz, 2009; Young, 2005). A second approach, adopted here, instead specifies environmental water use as a constraint on flow at a model node or along a link. Then (i) change the constraint level through sensitivity analysis, or (ii) examine the shadow value associated with the constraint to identify the opportunity cost of environmental water(Harou et al., 2009). Shadow values (Lagrange multipliers; dual variables) are model outputs and specify how system-wide net benefits change where the constraint was relaxed by one unit (such as $1 \mathrm{~m}^{3}$ ).

This second approach to environmental water use parallels other constraint-based methods to represent operating rules, policies, or proscribe delivery requirements to certain nodes or demand sectors. Thus, the hydro-economic model does not make water policy nor recommend environmental water use levels; rather, it identifies water allocations that perfectly obey imposed policies and environmental uses and reports resulting hydrologic, economic, and other impacts.

\section{WAS model and extensions}

The hydro-economic WAS model is a steady-state, nonlinear optimization program that identifies withdrawals from sources, deliveries through conveyance links between districts, and allocations to water use sectors within districts that maximize regional net benefits (Fisher et al., 2005). The single-year version for Israel, Jordan, and Palestine includes demands of 17.4 million people in urban, industrial, and agricultural sectors spread across 45 districts, 109 links, and 91 supply sources (Fig. 1), fresh and recycled water qualities, and country-specific price policies (Fisher et al., 2005). A stochastic version adds hydrologic variability, leak reduction, water conservation programs, plus conveyance, recycling, desalination, and source capacity expansion decisions (Rosenberg et al., 2008). The stochastic version has as an objective function to maximize expected regional net benefits. Expected net benefits are net benefits in each water 


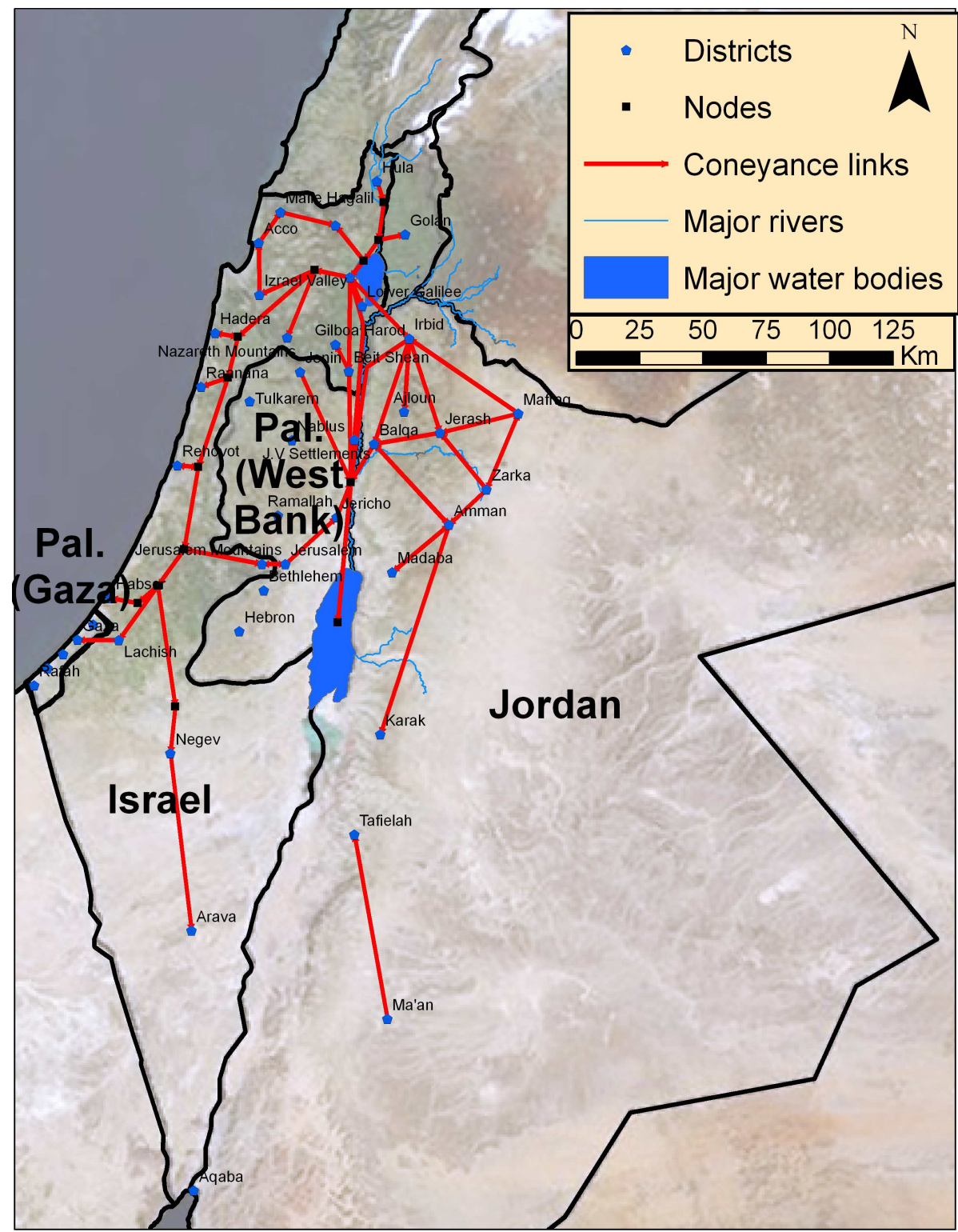

Fig. 1. Schematic of the existing inter-tied water systems for Israel, Palestine, and Jordan used in the extended Water Allocation System model. Urban, industrial, and agricultural water demands are located at districts while nodes represent intermediary points to transfer freshwater, recycled water, or agricultural return flows that are naturally or artificially conveyed along links.

availability event weighted by the event probability (likelihood). Expected net benefits include expected benefits from all agricultural, municipal, and industrial water uses minus expected withdrawal, treatment, conveyance, wastewater treatment, and other operational costs and minus one-time capital costs for infrastructure expansions and conservation program developments.

The work here extends the single-year and stochastic versions to include and allow return flows from agriculture, brine waste from desalination, multiple water quality types to meet a minimum in-stream flow requirement, and fixed-increment infrastructure capacity expansions. These extensions represent important components of flow balance for the Dead Sea, flow requirements to restore the Dead Sea level, and limits to build large infrastructure such as the Red-Dead projects. These extensions help assess Dead Sea restoration alternatives, are implemented as one or more new optimization program constraint(s), and are discussed further below.

\subsection{Return flows from agriculture}

In the single-year and stochastic versions of WAS, agricultural wastewater (return flow) cannot be reused, is assumed 
to have no economic value, and is not considered or quantified. However, agriculture wastewater is currently a large component of lower Jordan River flows and Dead Sea inflows. When increasing flow to the Dead Sea in a water scarce region or reallocating water away from agriculture, return flows do have a use and economic value. Thus, it is important to quantify and account for them.

The extended model adds a third water quality type, return flow, to the fresh and recycled water qualities already included. This addition generates a new mass balance constraint in each district $i$ for the new water quality type $q_{\text {return flow: }}$

$$
\begin{aligned}
\text { Water Use }_{\mathrm{i}, \mathrm{q}} & =\left(\begin{array}{l}
\text { Local Sources }_{\mathrm{i}, \mathrm{q}}+\text { Imports }_{\mathrm{i}, \mathrm{q}} \\
- \text { Exports }_{\mathrm{i}, \mathrm{q}}+\text { Reused Wastewater }_{\mathrm{i}, \mathrm{q}}
\end{array}\right)(1) \\
& \cdot\left(1-\text { Loss Rate }_{\mathrm{i}, \mathrm{q}}\right), \forall \mathrm{i}, \mathrm{q} \in \text { return flow. }
\end{aligned}
$$

We can then enter data to (i) restrict sectors from using return flows to satisfy economic demands, and (ii) indicate there is no leakage or local sources of this quality type. These conditions reduce Eq. (1) to:

$$
\begin{aligned}
0= & \left(\text { Imports }_{\mathrm{i}, \mathrm{q}}-\text { Exports }_{\mathrm{i}, \mathrm{q}}+\text { Reused Wastewater }_{\mathrm{i}, \mathrm{q}}\right), \\
& \forall \mathrm{i}, \mathrm{q} \in \text { return flow. }
\end{aligned}
$$

Here, imports, exports, and reused wastewater are the only active terms in the return flow accounting. The former two terms are included by specifying conveyance links for return flows among districts and nodes; in this case, the districts near or that can deliver return flows to the Jordan Valley and Dead Sea. The latter term is defined by only allowing the agriculture sector to contribute wastewater and specifying a non-consumptive fraction of the original use that becomes available as the return flow. This definition mimics an existing constraint that allows the agricultural sector to reuse treated wastewater from the urban and industrial sectors (for return flows, there is no physical wastewater treatment infrastructure). I use a non-consumptive fraction of $33 \%-$ as suggested by the literature - and test this assumption by comparing computed return flows to the lower Jordan River to observed flows under the existing management regime. Together, the additional constraint, data entry, and parameter specification allow us to include and model returns flows from agriculture.

\subsection{Brine waste from desalination}

Brine waste from desalination is also not included in the single-year and stochastic versions of WAS because the waste is assumed to have no use nor economic value. However, brine waste from the Red-Dead project could be delivered to Dead Sea and used in lieu of fresh, recycled, or agricultural return flows to raise the Dead Sea level. In this situation, which allowing mixing brine waste with other water quality types and Dead Sea water, brine waste does have economic value; it is important to include and quantify these effects.

We can further modify constraint Eq. (1) to include the volume of brine waste of water quality type $q$ available at district $i$ :

$$
\begin{aligned}
\text { Water Use }_{\mathrm{i}, \mathrm{q}} & =\left(\begin{array}{l}
\text { Local Sources }_{\mathrm{i}, \mathrm{q}}+\text { Imports }_{\mathrm{i}, \mathrm{q}}+\text { Brine }_{\text {Waste }} \text { - }_{\mathrm{i}, \mathrm{q}} \\
- \text { Exports }_{\mathrm{i}, \mathrm{q}}+\text { Reused Wastewater }_{\mathrm{i}, \mathrm{q}}
\end{array}\right)(3) \\
& \cdot\left(1-\text { Loss Rate }_{\mathrm{iq}}\right), \forall \mathrm{i}, \mathrm{q},
\end{aligned}
$$

and define this available volume with a new constraint that ties the brine waste volume to a user-specified fractional amount of the desalinated water produced:

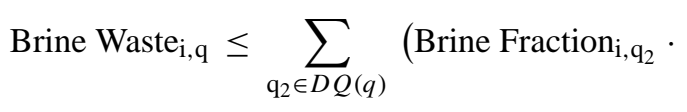

$$
\text { Desalinated Water } \left.\text { Produced }_{\mathrm{i}, \mathrm{q}_{2}}\right) \forall \mathrm{i}, \mathrm{q} \text {. }
$$

Here, the desalinated water produced is one of several terms embedded in the Local Sources term in Eqs. (1) and (3). The brine fraction is a unitless ratio that represents the volume of brine generated for each $1 \mathrm{~m}^{3}$ of desalinated water produced. $D Q(q)$ is a user-specified set of source water quality types $\left(q_{2}\right)$ that, when desalinated, generate brine quality $q$. For simplicity, we can lump brine waste and agricultural return flows into one water quality type, return flows. Here, use of brine waste is considered strictly on an additive volume basis and ignores water quality considerations and concerns that may arise when mixing Red Sea desalinated brine waste with Dead Sea water.

Current proposals suggest the Red-Dead project will generate $1 \mathrm{~m}^{3}$ of brine waste for each $1 \mathrm{~m}^{3}$ of desalinated water produced. I use this brine fraction value and also test the effects of this assumption through sensitivity analysis.

\subsection{Multiple water qualities can meet an in-stream flow requirement}

A third extension allows multiple water quality types to, on average, meet a minimum in-stream flow-requirement. The single-year WAS model hard-coded a flow requirement to ensure Israel supplied Gaza with freshwater; Rosenberg et al. (2008) made the requirement general to allow the user to specify a minimum required flow for any quality $q$ along any conveyance link from district $i$ to district $j$ in each stochastic water availability event $e$ :

$$
\begin{aligned}
\text { Conveyance Flow }_{\mathrm{q}, \mathrm{i}, \mathrm{j}, \mathrm{e}} \geq & {\text { minimum required } \text { flow }_{\mathrm{q}, \mathrm{i}, \mathrm{j}},} \\
& \forall \mathrm{q}, \mathrm{i}, \mathrm{j}, \mathrm{e} .
\end{aligned}
$$

We can extend this constraint to allow multiple flows of different quality types to count towards the minimum required flow 


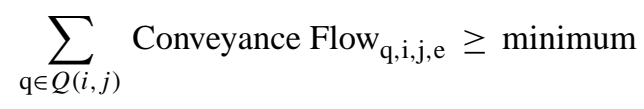

$$
\text { required flow }, \mathrm{i}, \forall \mathrm{i}, \mathrm{j}, \mathrm{e},
$$

and further, the expected flow to satisfy the minimum flow requirement rather than in each and every event:

$$
\begin{aligned}
& \sum_{\mathrm{e}}\left(\text { probability }_{\mathrm{e}} \cdot \sum_{\mathrm{q} \in Q(i, j)}{\text { Conveyance } \left.\text { Flow }_{\mathrm{q}, \mathrm{i}, \mathrm{j}, \mathrm{e}}\right)}^{\geq \text {minimum required } \text { flow }_{\mathrm{i}, \mathrm{j}}, \forall \mathrm{i}, \mathrm{j} .}\right.
\end{aligned}
$$

In Eqs. (6) and (7), probability is the likelihood that event $e$ will occur and $Q(i, j)$ is a user-specified set of water quality types whose flows can count towards the expected minimum required flow along the link from $i$ to $j$. For required deliveries to the Dead Sea, $Q(i, j)$ includes all water quality types (fresh, recycled, and return flows).

Equation (6) represents an absolute requirement that must be satisfied in every event while Eq. (7) represents a more relaxed requirement that need only be satisfied on average. The model user has the choice of which requirement type to apply on each conveyance link. And, as mentioned previously in Sect. 3.2, this addition of multiple water quality types to meet the absolute or expected flow requirement ignores water quality considerations and concerns that may arise from mixing Red Sea desalinated brine waste with Dead Sea water.

\subsection{Fixed-increment infrastructure expansions}

A fourth and final extension adds additional constraints and integer decision variables to limit infrastructure capacity expansion decisions to fixed increments. Prior work allowed continuous expansions of desalination, local source, conveyance, and wastewater treatment infrastructure up to a maximum capacity (Rosenberg et al., 2008). That approach works when proposed expansions are small and/or capital costs for expansions scale linearly with the expansion size. However, those assumptions do not hold for large capacity expansions such as coastal desalination plants or the RedDead project that can only be built in phases, to full capacity, or not at all.

Here, we can use integer decision variables and constraints to limit expansions to fixed increments. For expansion of local sources or desalination facilities, these limits are:

Local Source Expansion $_{\mathrm{i}, \mathrm{q}}=$ Capacity Interval $_{\mathrm{i}, \mathrm{q}}$

$$
\text { - } \text { LEVEL }_{\mathrm{i}, \mathrm{q}}, \forall \mathrm{i}, \mathrm{q} \text {, }
$$

where Local Source Expansion is the expansion size $\left(\mathrm{MCM} \mathrm{yr}^{-1}\right)$ for district $i$ and water quality type $q$ used elsewhere in the model, Capacity Interval is the fixed capacity expansion interval associated with each expansion level
( $\mathrm{MCM} \mathrm{yr}^{-1} /$ level), and LEVEL is an integer variable that represents the number of expansions implemented and takes values $[0,1,2, \ldots]$ up to the maximum allowed expansion levels. Equation (8) forces Local Source Expansion to take step capacities $0,1 \times$ Capacity Interval, $2 \times$ Capacity Interval, ..., Maximum Expansion Level $\times$ Capacity Interval. And when a particular capacity expansion project can only be built to maximum capacity or not built (such as for the Red-Dead project), LEVEL becomes a binary variable that takes the values $[0,1]$. Including these constraints and decision variables turns the model into a mixed-integer, non linear program (MINLP) that can be formulated and solved in the General Algebraic Modeling System (GAMS) with first CONOPT and then DICOPT (Brooke et al., 1998; Grossmann et al., 2002). This cascade of solvers starts with CONOPT for the relaxed mixed-integer, non linear problem (where interger variables can vary continuously) to ensure the solution is feasible. Subsequently, DICOPT identifies the MINLP solution. While DICOPT can not guarantee a global optimal solution to the MINLP, the cascade of solvers assures the relaxed and MINLP solutions are similar. Notation for the full optimization program, including the objective function, constraints, and decision variables, is available online as Supplemental Material.

\section{Model data}

The extended WAS model uses supply, conveyance, demand, wastewater treatment, and policy data for Israel, Jordan, and Palestine collected between 1995 and 2003 (Fisher et al., 2005) and updated for Jordan in 2006 (Rosenberg et al., 2008). This section presents updated data for each country, costs for the Red-Dead project, and describes how the three countries' inter-tied water systems are represented.

\subsection{Israel}

Since 2003, Israel has embarked on an ambitious program to build seawater desalination plants along its Mediterranean coast (Dreizin, 2006; Dreizin et al., 2008). Currently, 3 plants in Ashkelon, Palmachim, and Hadera are operational with a total capacity of $268 \mathrm{MCM} \mathrm{yr}^{-1}$. New plants at Ashdod and Soreq are under construction and should open in 2012 with additional capacity of $250 \mathrm{MCM} \mathrm{yr}^{-1}$. These plants are modeled with these existing capacities and operational costs ranging from $\$ 0.54$ to $0.75 \mathrm{~m}^{-3}$. Project tender amounts serve as the upper bound on capital costs to further expand these plant capacities towards Israel's desalination target of $750 \mathrm{MCM} \mathrm{yr}^{-1}$. Capital costs for these expansion options are included in a scenario that examines new decentralized infrastructure expansions and conservation program developments.

Israel groundwater availability is represented as constant from year to year whereas availability of Upper Jordan River 
surface water sources (to the districts of Golan, Hula, and the Sea of Galilee) are variable with variability characterized by sorting into increasing order the 60 -year record of water availability to the Sea of Galilee between 1950 and 2010 (Givati and Rosenfeld, 2007) (availability = stream flow + spring flows + direct rainfall - evaporation; excludes upstream consumptive use). I partition the distribution of water availability into a discrete set of 6 availability events whose mass probabilities correspond to the mass probabilities used previously for Jordan (Rosenberg et al., 2008). For each event, I pull the representative availability value from the sorted distribution and divide by the mean observed availability over the 60 -year record $\left(443 \mathrm{MCM} \mathrm{yr}^{-1}\right)$. This division gives an event-specific availability factor and allows use of a singleset of water availability events for diverse locations in Jordan and Israel that have different probability distributions of water availability. Finally, we multiply source availabilities by event- and source-specific availability factors to estimate source availability in each event.

A constant groundwater availability precludes modeling storage or groundwater banking decisions (that may allow managers to shift water from one water availability event to another) (Rosenberg et al., 2008). However, the limit forces use within groundwater safe yield, ensures a longterm sustainable use of groundwater resources, and counteracts the practice of groundwater mining (withdrawing above the aquifer safe yield), which is common throughout the region.

\subsection{Jordan}

Since 2006, Jordan has completed several projects that were previously under study. The Zara-Ma'een project to desalinate brackish-water now delivers $47.5 \mathrm{MCM} \mathrm{yr}^{-1}$ to Amman. The Zai pumping plant capacity was doubled and can now convey up to $90 \mathrm{MCM} \mathrm{yr}^{-1}$ from Balqa to Amman. An upgraded Al-Samra waste-water treatment plant can now accommodate up to $97.5 \mathrm{MCM} \mathrm{yr}^{-1}$ of municipal and industrial sewage from Amman. This infrastructure is all modeled with these specified existing capacities.

In late 2006, Jordan also completed the Unity Dam on the Yarmouk River. The dam has a total storage capacity of $110 \mathrm{MCM}$ and could increase Jordan's ability to divert Yarmouk water from 128 to $208 \mathrm{MCM} \mathrm{yr}^{-1}$. However, the dam has yet to fill and has stored only a paltry 7 to $30 \mathrm{MCM} \mathrm{yr}^{-1}$ (Namrouqa, 2009, 2010). Low storage is likely due to significant upstream abstractions and consumptive use by Syria (Rosenberg, 2006) and has prompted Jordan to ask Syria to release water to fill the dam (Namrouqa, 2010). Given the dam's low storage levels and yield to date, the extended model only allows up to $146 \mathrm{MCM} \mathrm{yr}^{-1}$ abstraction from the Yarmouk River as a local supply to Irbid.
Finally, the model keeps water efficiency improvements for urban users, leak reduction programs, Disi aquifer and conveyance to Amman and Aqaba, wastewater treatment for Aqaba and Zarqa, and local source developments for Aqaba as potential water conservation programs and infrastructure capacity expansions (Rosenberg et al., 2008). These programs are examined in a scenario that represents new, decentralized infrastructure expansions and conservation program developments.

\subsection{Palestine}

Despite difficult political circumstances, there have been notable water resources developments in the West Bank and Gaza since 2003 (Fisher et al., 2005). Two small seawater desalination plants with capacities of $1.8 \mathrm{MCM} \mathrm{yr}^{-1}$ operate in North Gaza and Dier Al-Balah. Wastewater treatment plants operate in the West Bank and Gaza with capacities that range from, respectively, 0.44 to 8.9 and 15 to $40 \mathrm{MCM} \mathrm{yr}^{-1}$. Recent studies by the Palestinian Water Authority (PWA) and others call to expand conveyance, desalination, and wastewater treatment and reuse in Gaza at capital costs of, respectively, $\$ 0.3, \$ 2.7$, and $\$ 1.2$ million/MCM. Although the Palestinian water distribution system has many leaks, the current analysis assumes PWA will reduce physical leakage to $20 \%$.

\subsection{Red-Dead project}

This study locates the Red-Dead project and its conveyance, desalination, and hydropower generation facilities entirely in Jordan. It considers two project configurations and optimistically estimates capital and operating costs from recent newspaper reports and official Jordanian statements (Table 1). Actual costs are likely larger so optimistic estimates provide a lower-bound basis to determine project feasibility. The first Red-Dead project configuration includes the canal, desalination at Balqa (near the Dead Sea), delivery of brine waste to the Dead Sea, conveyance from Balqa to Amman, and represents the current proposal by Jordan, Israel, and the Palestinians. A second configuration includes only the canal and hydropower generation at Balqa with tail water delivered to the Dead Sea. Here, operational costs are negative and represents profits of approximately $\$ 0.05$ per $\mathrm{kW}$-h generated (Hrayshat, 2008, 2009). We test the effect of hydropower operational cost through sensitivity analysis.

\subsection{Inter-tied water system}

Representing the Red-Dead project, Dead Sea, and return flows in a combined, inter-tied model for the three countries (Fig. 1) required several modifications. First, new nodes were added for the lower Jordan River and Dead Sea. Second, new links for all qualities at zero operational cost were specified from (a) Biqaat Kinerrot and Beit Shean (in Israel), (b) Irbid and Balqa (in Jordan), and (c) Jenin and Jericho (in 
Table 1. Capital and Operating Costs Used to Model Red-Dead Project Configurations.

\begin{tabular}{|c|c|c|c|}
\hline Configuration & $\begin{array}{l}\text { Capital Cost } \\
\text { (\$US billion) }\end{array}$ & $\begin{array}{r}\text { Operating Cost } \\
\qquad\left(\$ \mathrm{~m}^{-3}\right)\end{array}$ & Ref. \\
\hline $\begin{array}{l}\text { Canal, desalination, Amman conveyance, } \\
\text { and brine waste delivery to the Dead Sea }\end{array}$ & 4.1 & 1.14 & (Hussein, 2007) \\
\hline Canal and desalination & 2.6 & 0.92 & $\begin{array}{l}\text { (H. El-Nasser, personal } \\
\text { communication, 2005) }\end{array}$ \\
\hline Amman conveyance & 1.5 & 0.22 & $\begin{array}{l}\text { (Fisher et al., 2005; } \\
\text { H. El-Nasser, personal } \\
\text { communication, 2005) }\end{array}$ \\
\hline $\begin{array}{l}\text { Canal, hydropower, and tail water } \\
\text { delivery to the Dead Sea }\end{array}$ & 1.5 & -0.05 & (Hrayshat, 2008, 2009) \\
\hline
\end{tabular}

Palestine) to the lower Jordan River node, and (d) the Jordan River to the Dead Sea. Third, additional links for return flows at no operational cost were also added from West (Israel) to East Jerusalem (Palestine) and from East Jerusalem (Palestine) to Jericho (Palestine). These links all represent conveyance by gravity flow through existing wadis and channels to the Jordan River and Dead Sea. The new expected minimum flow requirement presented in Sect. 3.3 was specified along the last link from the Jordan River to the Dead Sea and used to make the hydro-economic analysis.

\section{Hydro-economic model results}

I ran the extended model for a base case representing existing infrastructure, demands forecast in 2020, fresh and recycled water use, and a Dead Sea flow requirement of $100 \mathrm{MCM} \mathrm{yr}^{-1}$ (A1 in Fig. 2). Scenario analysis shows impacts when considering agricultural return flows (A2 and A3), return flows with two Red-Dead project configurations (B and C) and with new decentralized water infrastructure plus conservation programs (Figs. 2 to 5 and Table 2). Sensitivity analysis shows how scenario net benefits and allocations change when increasing the expected required flow to the Dead Sea - the environmental water use constraint attached to the lower Jordan River conveyance link.

System-wide expected net benefits fall and expected costs rise as the required flow to the Dead Sea increases (Fig. 2). Rising expected costs reflect increasing water scarcity and reduced benefits as water is reallocated from agricultural, urban, and industrial water users to the lower Jordan River and Dead Sea. When the existing system (A1, using only fresh and recycled waters) returns approximately $900 \mathrm{MCM} \mathrm{yr}^{-1}$ to the Dead Sea, cost increases surpass a \$US726 million $\mathrm{yr}^{-1}$ benchmark that represent the non-market benefits from restoration measured by prior estimates of Israeli, Palestinian, and Jordanian willingness-to-pay (WTP) to restore the Dead Sea (Becker and Katz, 2009). These non-market WTP benefits include gross profits from Dead Sea mineral extractions, contigent value stated, and travel cost revealed preferences. These WTP benefits are not included in the extended model, but represent a benchmark against which to compare expected decreases in net benefits when a $900 \mathrm{MCM} \mathrm{yr}^{-1}$ threshold flow is achieved that hydrologists and limnologists advise is needed to stabilize the Dead Sea level at $-435 \mathrm{~m}$ (Yechieli et al., 1998). Model results suggest the existing system (A1) can flexibly reallocate and deliver additional water to the Dead Sea but cannot economically meet the $900 \mathrm{MCM} \mathrm{yr}^{-1}$ flow threshold.

Agricultural return flows (A2 and A3 in Fig. 2) serve an important economic role to reach downstream environmental objectives. Namely, decreasing the water consumptively used by agricultural and returning larger flows to the lower Jordan River reduces overall expected costs. Still, these cost reductions are not sufficiently large to make achieving the $900 \mathrm{MCM} \mathrm{yr}^{-1}$ Dead Sea flow threshold economical.

Expected costs associated with the Red-Dead project (B, configured to desalinate new supply and deliver brine waste to the Dead Sea as currently proposed by Jordan, Israel, and the Palestinians) are lower than the reallocation alternatives and the WTP benchmark. Interestingly, the program only finds benefit to build and operate the Red-Dead project when the Jordan River flow requirement is at or above $800 \mathrm{MCM} \mathrm{yr}^{-1}$. However, expected costs are lower still for a smaller Red-Dead project configuration (C) that only generates hydropower and delivers tail water to the Dead Sea or alternative (D) that builds new, decentralized local infrastructure and conservation programs across the three countries (Fig. 2). These alternatives are more economically viable than the Red-Dead project currently proposed by the three countries.

A sensitivity analysis shows the agricultural return flow and brine generation conditions for which it is viable to build the Red-Dead project (B) as proposed by the three countries (Fig. 3). Increasing agricultural return flows delay the need for the project and allow the existing system to meet larger 
Table 2. Price schedule for Dead Sea water purchases under different infrastructure and program alternatives using WAS model shadow value results ( $\$$ US per $\mathrm{m}^{3}$ ).

\begin{tabular}{ccccc}
\hline $\begin{array}{c}\text { Water volume } \\
\text { remaining to be } \\
\text { delivered in the year } \\
\text { (MCM) }\end{array}$ & $\begin{array}{c}\text { A2. Existing } \\
\text { system with } \\
\text { agriculture return } \\
\text { flows (33\%) }\end{array}$ & $\begin{array}{c}\text { B. Red-Dead } \\
\text { project, } \\
\text { desalination and } \\
\text { brine waste } \\
\text { delivery }\end{array}$ & $\begin{array}{c}\text { C. Red-Dead } \\
\text { project, } \\
\text { hydropower and } \\
\text { tail water delivery }\end{array}$ & $\begin{array}{c}\text { D. New local } \\
\text { infrastructure and } \\
\text { water } \\
\text { conservation } \\
\text { programs }\end{array}$ \\
\hline 100 & 0 & 0 & 0 & 0 \\
200 & 0 & 0 & 0 & 0 \\
300 & 0.12 & 0.12 & 0.12 & 0.09 \\
400 & 0.43 & 0.43 & 0 & 0.27 \\
500 & 0.53 & 0.53 & 0 & 0.45 \\
600 & 0.67 & 0.67 & 0 & 0.53 \\
700 & 0.86 & 0.86 & 0 & 0.63 \\
800 & 1.65 & 1.65 & 0 & 0.88 \\
900 & 6.26 & 0.46 & 0 & 0.88 \\
1000 & 35.59 & 0.46 & 0 & 1.12 \\
\hline
\end{tabular}

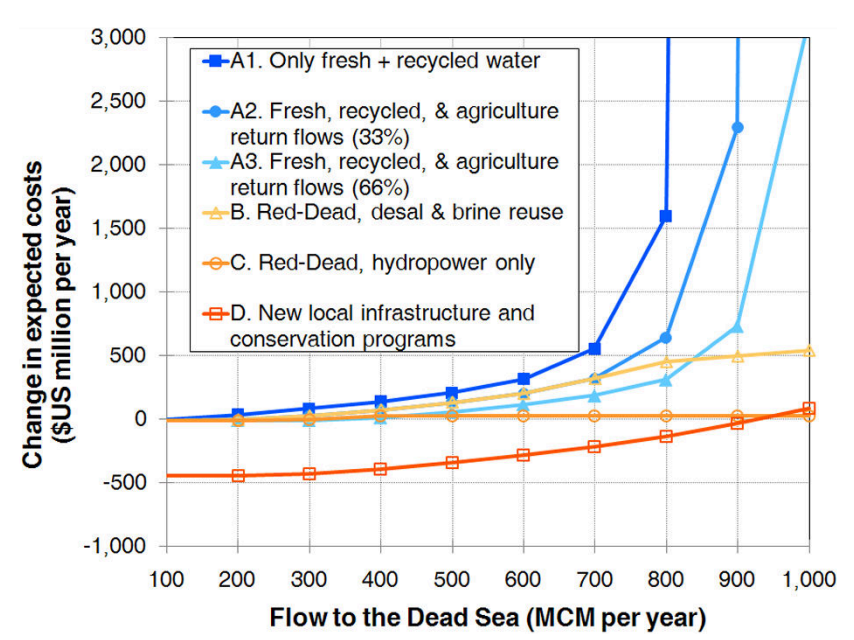

Fig. 2. Economic impacts for six restoration alternatives when increasing required flow to the Dead Sea. Change on the y-axis is quantified as expected net benefits observed for the base case alternative A1 that allows reallocations, uses only fresh + recycled water, and delivers just $100 \mathrm{MCM} \mathrm{yr}^{-1}$ flow to the Dead Sea minus expected net benefits for the specified alternative at the specified Dead Sea flow requirement.

Dead Sea flow requirements with lower expected costs. In contrast, larger brine fractions that produce more brine volume for each $1 \mathrm{~m}^{3}$ of desalinated freshwater provide an incentive to build the project earlier at smaller required flows to the Dead Sea. This result occurs because larger brine fractions provide more brine water to meet the Dead Sea flow requirement. Expected costs are the same up until the points where the project is built; at larger required flows to the Dead Sea where the project is built, larger brine fractions lower overall expected costs to meet the required flow. These sensitivity results highlight needs to consider agricultural return flows, brine generation, and other environmental water inputs when determining new infrastructure and operations to meet downstream environmental flow requirements.

The three viable restoration alternatives identified in Fig. 2 distribute benefits and desalination responsibilities differently among the three countries (Fig. 4). Jordan principally bears costs to operate the Red-Dead project and satisfy larger Dead Sea flow requirements whiles Israel cuts back some Mediterranean coastal desalination (B). With a smaller RedDead project that just generates hydropower (C), Jordan still exclusively bears the project costs. Costs, benefits, and desalination responsibilities switch with a decentralized mix of new local infrastructure and conservation programs (D). Initially, Israel cuts back coastal desalination while expected benefits accrue mostly to Jordan. However, as required flows to the Dead Sea increase, Israel increases coastal desalination and faces increased expected costs. When considering an estimated split in WTP benefits from Dead Sea restoration among Israel, Jordan, and Palestine of \$363, \$339, and \$23 million $\mathrm{yr}^{-1}$, respectively (Becker and Katz, 2009), only the smaller Red-Dead project that just generates hydropower (C) will produce sufficient individual benefits for each country.

\section{Implications for governance}

For all alternatives, expected costs rise as the required flow to the Dead Sea increases (Figs. 2 to 4). Increases reflect increasing water scarcity and show each country currently has little or no individual economic incentive to deliver water to the Dead Sea. Absent a requirement, countries would rather put water to beneficial use and have other countries return water to the Dead Sea. This incentive structure contributed to the current full use of Jordan River water and will likely 
I. Red-Dead project expansion (Do not build or Build)
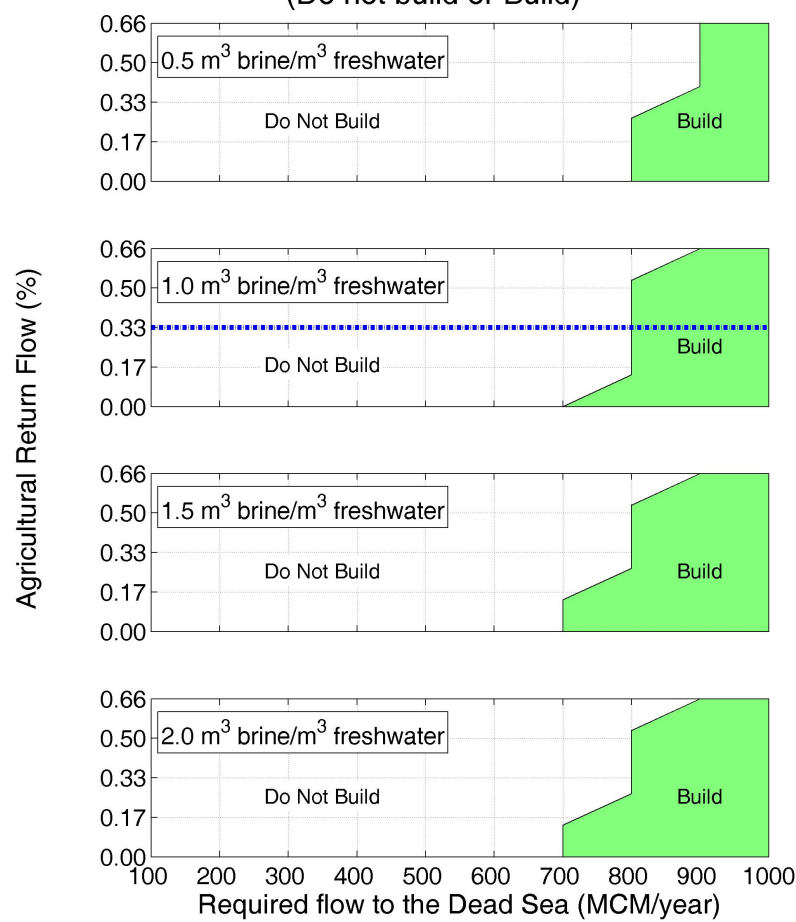

II. Change in expected costs (\$US million/year)
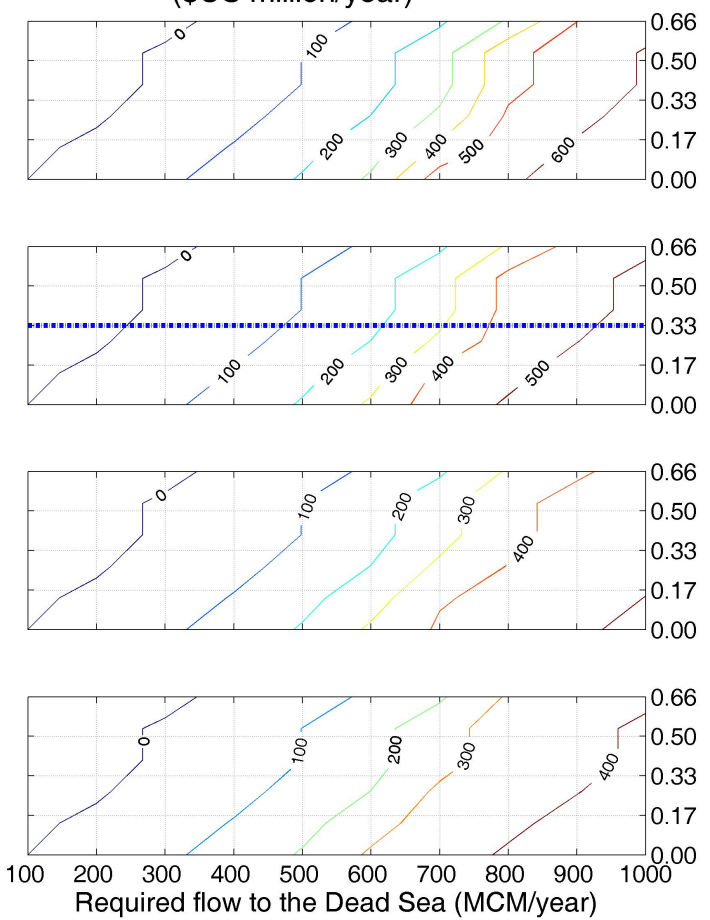

Fig. 3. Sensitivity analysis shows how the decision to build the Red-Dead project (I. left panels) and change in expected costs (II. right panels) are influenced by agricultural return flows (y-axes), the brine generation ratio (panel rows), and required flows to the Dead Sea (x-axes). Changes in expected costs (II. right panels) are defined as in Fig. 2. The brine generation ratio is the $\mathrm{m}^{3}$ of brine waste generated for each $1 \mathrm{~m}^{3}$ of desalinated freshwater produced. Dashed blue lines indicate default agricultural return flow and brine generation parameter values used elsewhere to evaluate Red-Dead project options B and C.

continue should new infrastructure like a Red-Dead project be built.

New infrastructure alone will not raise the Dead Sea level. Third parties and institutions outside the basin - such as the World Bank or environmental groups - that seek to raise the Dead Sea level must also create incentives for countries to deliver water to the Dead Sea. First, outside institutions could offer countries financial incentives such as pay the full capital cost of the Red-Dead project (annualized at \$US 330 million $\mathrm{yr}^{-1}, 5 \%$ interest, continuous compounding, 20-year project life) to encourage the countries to agree on the water volumes each will deliver to the Dead Sea. Yet even with this incentive, a decentralized mix of new local infrastructure and conservation programs is still a more economically viable alternative to raise the Dead Sea level.

\subsection{Pay countries to deliver water to the Dead Sea}

Alternatively, outside institutions could pay countries to deliver water to the Dead Sea. Model results show that the scarcity value of water is large (Table 2). This scaricty value is the shadow value (Lagrange multiplier) associated with the minimum in-stream flow constraint and describes the decrease in overall net benefits were the flow requirement raised one unit. Shadow values have units of $\$ / \mathrm{m}^{3}$ and describe the minimum price a country would require to forgo use of the water and allow the water to flow to the Jordan river. Generally, shadow values rise as the Jordan River flow requirement increases and water becomes more scarce (Table 2). Exceptions occur (Table 2, columns B and C) when increased flow requirements trigger new large infrastructure projects that have substantial capital costs but are not immediately operated at full capacity. After the projects are built and as the flow requirement further increases, the shadow value reflects the operational cost to bring online unused capacity. However, in all cases, shadow values are positive and large so countries will prefer to beneficially use the water rather than deliver it to the Jordan River and Dead Sea.

An outside institution could purchase water from the countries with purchases occurring only when purchase prices (i) exceed the scarcity (and other) costs borne by users in the country selling the water, but are (ii) less than the environmental value of water returned to the Dead Sea. There are several common objections to market-based water purchases (Richards and Singh, 2001) and responses (Fisher and Huber-Lee, 2009; Fisher et al., 2005). Here, I address issues 

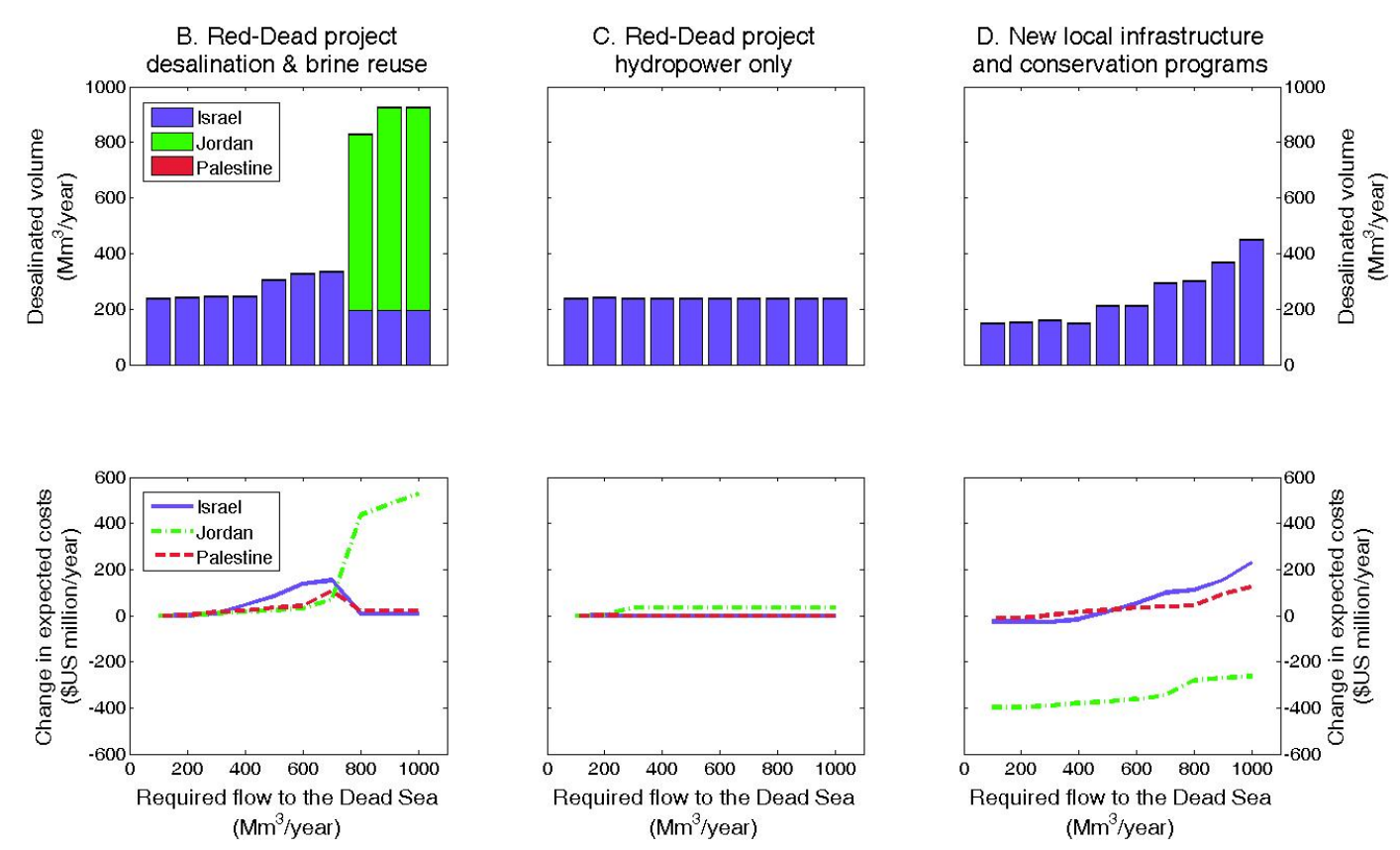

Fig. 4. Country-specific impacts for three more-promising restoration alternatives (B, C, and D). Desalination volumes (top panels) are desalination operations during the most extreme water availability event when surface water flows in Jordan and the Upper Jordan River are, respectively, $48 \%$ and $44 \%$ of their historical averages. Changes in expected costs (bottom panels) are defined as in Fig. 2.

to purchase water for environmental purposes (Murphy et al., 2009). First, the most effective market will involve a grand coalition of all countries (although one or more countries may only nominally participate) (Fisher and Huber-Lee, 2009). Second, no countries may choose to sell. Although, at some (possibly large) price, a country will find the payment sufficient compensation for the scarcity costs it incurs and sell water. Third, countries could collude to raise prices. While possible, collusion will likely be temporary. As offer prices rise, a country will have a strong incentive to defect and sell. Fourth, the sale price need not stay constant and can vary with environmental, hydrological, and other conditions such as the water volume already purchased.

Setting appropriate sale prices is key to establish a successful market for environmental purchases. And WAS model shadow values for water to meet the Dead Sea flow constraint (Table 2) can help guide price setting (Fisher and Huber-Lee, 2009; Fisher et al., 2005). These shadow values represent the scarcity value of water and minimum price an outside institution must offer to successfully purchase water from a country. A regressive schedule based on shadow value model results (Table 2) could set prices at or above the shadow value associated with the delivery volume still remaining to meet the annual target.

The present values of annual payments to countries to deliver water to the Dead Sea are large and typically exceed capital costs for new infrastructure (Fig. 5). Payments and capital costs under the existing system (A2) exceed the estimated \$US 8.9 billion present value of the annual WTP benchmark that represents benefits to restore the Dead Sea (20 year life, 5\% interest, continuous compounding). Lower payments and capital costs for the Red-Dead project proposed by the three countries (B) and decentralized mix of new local infrastructure and conservation programs (D) are at or slightly below the WTP benchmark. Costs are lowest for the smaller Red-Dead project configured to only generate hydropower $(\mathrm{C})$ and are principally to build new infrastructure (canal, turbines, and generators). Here, payments are needed only to purchase flows up to $300 \mathrm{MCM} \mathrm{yr}^{-1}$ before the project is built. Above this level, Jordan builds and profitably generates hydropower at full capacity, the Dead Sea flow constraint does not bind, and the associated shadow value is zero. Although payments to countries significantly raise costs to return flows to the Dead Sea, WTP benefits from restoration often surpass the payments and capital costs.

\subsection{Hydropower operating cost sensitivity analysis}

Results in Figs. 4 and 5 suggest the Red-Dead project operated only to generate hydropower and deliver tail water to the Dead Sea is the most economically viable of the alternatives considered. Namely, present value costs for new infrastructure plus payments to countries to deliver water are substantially below the estimated present value of WTP benefits from restoration. Yet this viability is sensitive to the RedDead project hydropower operating cost (Fig. 6). Should either the sale price for generated energy fall or we include project operations and maintenance costs, Jordan would still 


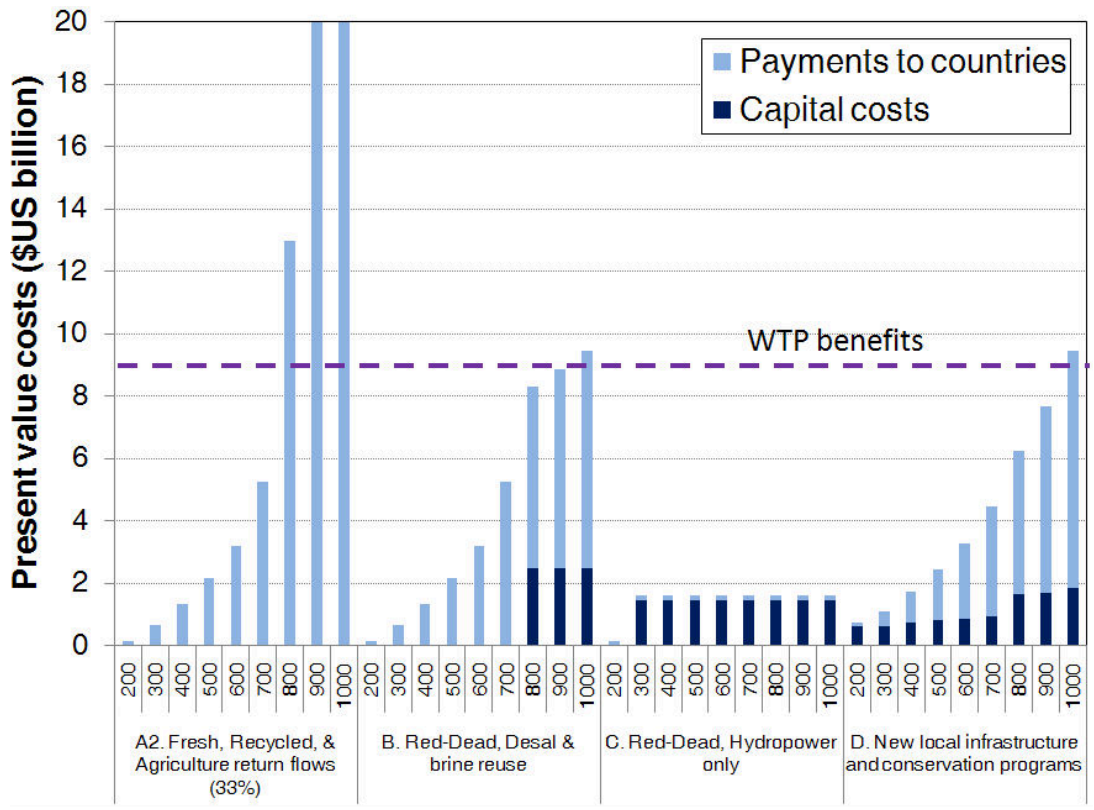

Fig. 5. Present value costs for each alternative including capital costs for new infrastructure and programs and payments to countries to deliver the specified flow to the Dead Sea. Payments to countries are based on the shadow value price schedule in Table 2. Payments are compared to the present value of an annual WTP benchmark estimated by Becker and Katz (2009) that represents benefits to restore the Dead Sea.

build the Red-Dead project, but operate the project at less than capacity and only to meet the Dead Sea flow requirement. There would be a shadow value associated with delivering water to the Dead Sea and Jordan would likely seek annual payments to deliver the water to the Dead Sea. The present value of these payments would comprise several billion dollars and approach payments associated with other Dead Sea restoration alternatives. These results suggest the economic viability of a smaller Red-Dead project that only generates hydropower is sensitive to the sale price of generated electricity, operations and maintenance costs; these project aspects require further study.

\subsection{Limitations}

The hydro-economic model is a steady-state model that represents a long-run, future equilibrium. Results focus on the end state but do not describe the dynamic transition from the current to future state (such as when new infrastructure should be built or payments started). Additionally, recommended solutions, on average, deliver water to the lower Jordan River to meet an expected-value in-stream flow condition, but do so by both surpassing and not reaching the annual target in years with, respectively, high and low (surface) water availability. Still, deliveries in low availability years far surpass the current paltry $100 \mathrm{MCM} \mathrm{yr}^{-1}$ Jordan River flow to the Dead Sea. Such flow variations above and below the required flow are acceptable for resilient environmental systems - such as the lower Jordan River and Dead Sea - where restoration objectives are largely hydrologic and/or systems do not face (or have already surpassed) ecological thresholds. For threatened systems that face thresholds beyond which recovery is not possible, absolute minimum flow criteria should instead be implemented. In the Jordan River basin, were an absolute flow criteria instead used, model results (not shown) indicate a much larger need for desalination, higher shadow values, and larger payments to countries to deliver water to the Jordan River.

Model results and implications for governance also do not consider the environmental effects of mixing Red- and Dead Sea waters, adding brine waste from desalinated Red Sea water to Dead Sea water, or locating a large project intake facility at the north end of the Red Sea in the Eilat/Aqaba environmental and tourist zone. Currently, the World Bank is identifying effects and remediation strategies and quantifying remediation costs. Still, even with small remediation costs, model results show other alternatives are more economically viable than the Red-Dead project currently proposed by the three countries. Further, remediation costs would exacerbate existing governance that encourages full use of Jordan River water and make it more difficult for countries to deliver water to the Dead Sea via the Red-Dead project. 


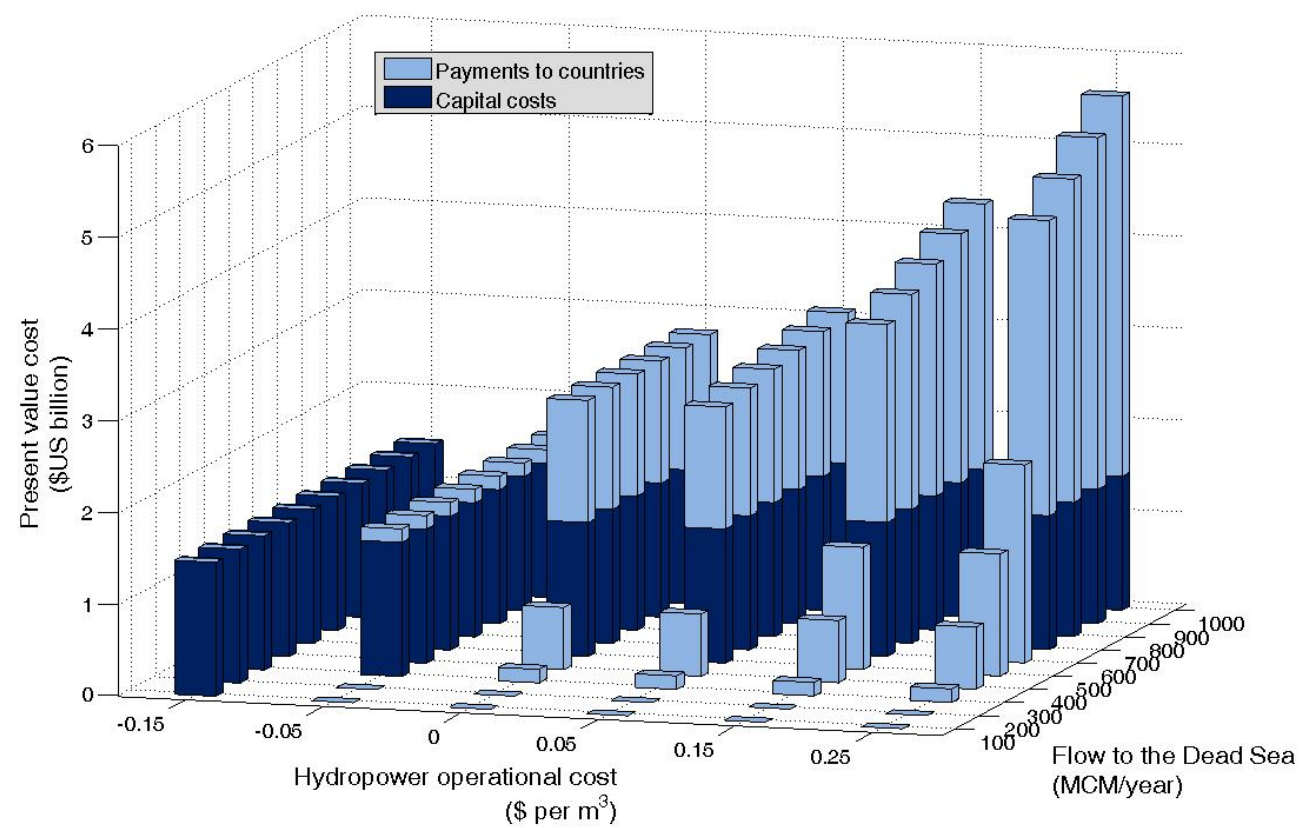

Fig. 6. Present value costs as a function of both the flow delivered to the Dead Sea and the hydropower operational cost for the Red-Dead project configuration that considers only the canal, hydropower generation, and tailwater delivery to the Dead Sea. Hydropower operation costs less than zero represent operational benefits.

\section{Conclusions}

A declining Dead Sea level and the associated land subsidence, sink holes, groundwater contamination, reduced mineral extraction and tourism, plus other problems, in part, have prompted Israel, Jordan, and the Palestinians to propose the Red-Dead project to raise the Dead Sea level. The project would build a large, expensive canal from the Red Sea to the Dead Sea and also generate hydropower and desalinated water.

Hydro-economic model results for the three countries' inter-tied water systems show two Dead Sea restoration alternatives - a (i) mix of decentralized new infrastructure and conservation programs in each country, or (ii) smaller RedDead project that only generates hydropower - are more economically viable than the larger Red-Dead project proposed by the three countries. These assessments consider important components of flow balance for the Dead Sea, flow requirements to restore the Dead Sea level, and limits to build large infrastructure such as the Red-Dead project. Flow balance components such as agricultural return flows and brine waste generation influence the conditions in which new infrastructure (such as the Red-Dead project) should be built and overall expected costs to meet downstream environmental flow requirements.

Results for all restoration alternatives show rising deliveries to the Dead Sea trigger increasing water scarcity and suggest each country has little individual incentive to allow water to flow to the Dead Sea. Beyond new infrastructure, outside institutions that seek to raise the Dead must also develop new governance that provides countries incentives to deliver water to the Dead Sea. One incentive - pay countries to deliver water - ties environmental water purchases to model shadow value results and the scarcity value of water. Payments will substantially raise actual Dead Sea restoration costs above the current estimated \$US 5 billion capital costs for the Red-Dead project. Payments for water and new infrastructure will also change the distribution of water, benefits, and costs among the three countries. Although payments are large, restoration benefits measured by willingness-topay estimates are larger still and identify several viable approaches to raise the Dead beyond the Red-Dead project proposed by the three countries.

\section{Supplementary material related to this article is available online at: http://www.hydrol-earth-syst-sci.net/15/1243/2011/ hess-15-1243-2011-supplement.pdf.}

Acknowledgements. In April 2010, CEE 6490 students used the stochastic version of the WAS model to identify economic impacts from returning an additional $200 \mathrm{MCM} \mathrm{yr}^{-1}$ to the Dead Sea. Charles Sims, Mac McKee, Gideon Oron, Richard Peralta, Samer Talozi, and Loay Hidmi gave feedback on earlier drafts.

Edited by: S. Thompson 


\section{References}

Arbitbol, E.: Giving the Dead Sea a New Life: Have All Options Been Responsibly Considered?, J. Peacebuil. Devel., 3, 94-99, 2006.

Asmar, B. N. and Ergenzinger, P.: Long-term prediction of the water level and salinity in the Dead Sea, Hydrol. Process., 16, 2819 2831, doi:10.1002/hyp.1073, 2002.

Beaumont, P.: Dividing the waters of the River Jordan: An analysis of the 1994 Israel-Jordan Peace Treaty, Water Res. Devel., 13, 415-424, 1997.

Becker, N. and Katz, D. L.: An Economic Assessment of Dead Sea Preservation and Restoration, in: The Jordan River and Dead Sea: cooperation amid conflict, edited by: Lipchin, C., Sandler, D., and Cushman, E., Springer, Dordretch, The Netherlands, 275-296, 2009.

Brooke, A., Kendrick, D., Meeraus, A., and Raman, R.: GAMS, a user's guide, GAMS Development Corporation, Washington, DC, 1998 .

Dreizin, Y.: Ashkelon seawater desalination project - off-taker's self costs, supplied water costs, total costs and benefits, Desalination, 190, 104-116, 2006.

Dreizin, Y., Tenne, A., and Hoffman, D.: Integrating large scale seawater desalination plants within Israel's water supply system, Desalination, 220, 132-149, 2008.

Fisher, F. M. and Huber-Lee, A.: WAS-guided cooperation in water: the grand coalition and sub-coalitions, Environ. Dev. Econ., 14, 89-115, doi:10.1017/s1355770x08004695, 2009.

Fisher, F. M., Huber-Lee, A., Amir, I., Arlosoroff, S., Eckstein, Z., Haddadin, M. J., Hamati, S. G., Jarrar, A. M., Jayyousi, A. F., Shamir, U., and Wesseling, H.: Liquid Assets: An economic approach for water management and conflict resolution in the Middle East and beyond, Resources for the Future, Washington, DC, 242 pp., 2005.

Givati, A. and Rosenfeld, D.: Possible impacts of anthropogenic aerosols on water resources of the Jordan River and the Sea of Galilee, Water Resour. Res., 43, W10419, doi:10.1029/2006wr005771, 2007.

Glausiusz, J.: New life for the Dead Sea?, Nature, 464, 1119-1120, 2010.

Grossmann, I. E., Viswanathan, J., Vecchietti, A., Raman, R., and Kalvelagen, E.: DICOPT: A Discrete Continuous Optimization Package, GAMS Development Corporation, Washington, DC, 2002.

Harou, J., Pulido-Velazquez, M., Rosenberg, D. E., MedellinAzuara, J., Lund, J. R., and Howitt, R. E.: Hydro-economic Models: Concepts, Design, Applications, and Future Prospects, J. Hydrol., 375, 627-643, doi:10.1016/j.jhydrol.2009.06.037, 2009

Howe, C. W. and Linaweaver, F. P.: Impact of Price on Residential Water Demand and Its Relation to System Design and Price Structure, Water Resour. Res., 3, 13-32, 1967.
Hrayshat, E. S.: Analysis of renewable energy situation in Jordan, Energy Sources Part B-Economics Planning and Policy, 3, 89102, doi:10.1080/15567240600815000, 2008.

Hrayshat, E. S.: Prospects of Hydropower Utilization for Electricity Generation in Jordan, Energy Source. Part B, 4, 77-83, 2009.

Hussein, M. B.: World Bank invites bids for Red-Dead feasibility study, Jordan Times, Amman, Jordan, 5 April, 2007.

Lensky, N. G., Dvorkin, Y., Lyakhovsky, V., Gertman, I., and Gavrieli, I.: Water, salt, and energy balances of the Dead Sea, Water Resour. Res., 41, W12418, doi:10.1029/2005wr004084, 2005.

Lowi, M. R.: Water and Power: The politics of a scarce resource in the Jordan River Basin, Cambridge University Press, Cambridge, 291 pp., 1993

Milliman, J. W.: Policy Horizons for Future Urban Water Supply, Land Econ., 39, 109-132, 1963.

Murphy, J. J., Dinar, A., Howitt, R. E., Rassenti, S. J., Smith, V. L., and Weinberg, M.: The design of water markets when instream flows have value, J. Environ. Manage., 90, 1089-1096, doi:10.1016/j.jenvman.2008.04.001, 2009.

Namrouqa, H.: Major dams one-third full after early rains, Jordan Times, Amman, Jordan, 26 November, 2009.

Namrouqa, H.: Jordan does not owe Israel a drop of water, Jordan Times, Amman, Jordan, 2010.

Raz, E.: The Future of the Dead Sea: is the Red Sea-Dead Sea conduit the right solution?, in: The Jordan River and Dead Sea: cooperation amid conflict, edited by: Lipchin, C., Sandler, D., and Cushman, E., Springer, Dordretch, The Netherlands, 189212, 2009.

Red Sea-Dead Sea Water Conveyance Study Environmental and Social Assessment: Initial Assessment Report, World Bank, 2010.

Richards, A. and Singh, N.: No easy exit: Property rights, markets, and negotiations over water, Int. J. Water Resour. D., 17, 409425, 2001.

Rosenberg, D. E.: The Yarmouk River Agreements: Jordan-Syrian transboundary water management, 1953-2004, Arab World Geographer, 9, 23-39, 2006.

Rosenberg, D. E., Howitt, R. E., and Lund, J. R.: Water Management with Water Conservation, Infrastructure Expansions, and Source Variability in Jordan, Water Resour. Res., 44, W11402, doi:10.1029/2007WR006519, 2008.

Salameh, E. and El-Naser, H.: Restoring the shrinking Dead Sea - the environmental imperative, in: Climatic Changes and Water Resources in the Middle East and North Africa, edited by: Zereini, F. and Hötzl, H., Springer, Berlin, Germany, 453-468, 2008.

Wolf, A. T.: Hydropolitics along the Jordan River, United Nations University Press, New York, NY, 1995.

Yechieli, Y., Gavrieli, I., Berkowitz, B., and Ronen, D.: Will the Dead Sea die?, Geology, 26, 755-758, 1998.

Young, R. A.: Determining the Economic Value of Water: Concepts and Methods, Resources for the Future, Washington, DC, 357 pp., 2005. 